\title{
Driving Pressure: Defining the Range
}

\author{
Arianne K Baldomero, Paula K Skarda, and John J Marini
}

\begin{abstract}
BACKGROUND: Recent literature suggests that optimization of tidal driving pressure $(\Delta P)$ would be a better variable to target for lung protection at the bedside than tidal volume $\left(V_{T}\right)$ or plateau pressure $\left(\mathbf{P}_{\text {plat }}\right)$, the traditional indicators of ventilator-induced lung injury. However, the usual range or variability of $\Delta P$ over time for any subject category have not been defined. This study sought to document the $\Delta \mathbf{P}$ ranges observed in current practice among mechanically ventilated subjects receiving routine care for diverse acute conditions in a community hospital environment. METHODS: This was a retrospective, observational study in a university-affiliated and house staff-aided institution with respiratory care protocols based on extant lung-protective guidelines for $\mathrm{V}_{\mathrm{T}}$. Demographic characteristics and measured parameters related to mechanical ventilation and hemodynamics were extracted from electronic records of intubated subjects for each 8-h period of the first $24 \mathrm{~h}$ in the ICU. $P_{\text {plat }}$ values reported by the ventilator were validated by the respiratory therapist before those data were entered into the electronic medical record. RESULTS: The mean $\Delta P$ was significantly higher at Time 1 (mean 16.1, range 7.0-31.0 $\mathrm{cm} \mathrm{H}_{2} \mathrm{O}$ ) compared to both Time 2 (mean 14.5, range 7.0-35.0 $\left.\mathrm{cm} \mathrm{H}_{2} \mathrm{O}\right)(P<.001$ ) and Time 3 (mean 14.8, range 8.0-32 $\left.\mathrm{cm} \mathrm{H}_{2} \mathrm{O}\right)(P<.001)$. At all time points, the median $\Delta \mathrm{P}$ was higher for completely passive breathing compared to triggered breathing. The widest difference between presumed entirely passive and presumed intermittently or consistently triggered breaths occurred at Time 1 (mean $\Delta P=17.2$ vs $14.9 \mathrm{~cm} \mathrm{H}_{2} \mathrm{O}$, respectively $)(P=.01)$. CONCLUSIONS: Suggested safety thresholds for $\Delta P$ are often violated by a strategy that focuses on only $V_{T}$ and $P_{\text {plat }}$ Our data suggest that $\Delta P$ is lower for passive versus triggered breathing cycles. Vigilance is especially important in the initial stages of mechanical ventilator support, and attention should be paid to triggering efforts when interpreting and comparing machine-determined numerical values for $\mathbf{\Delta} \mathbf{P}$. Key words: ventilators, mechanical; ventilatorinduced lung injury; lung injury; driving pressure; respiratory failure; ventilator settings. [Respir Care 2019;64(8):883-889. (C) 2019 Daedalus Enterprises]
\end{abstract}

\section{Introduction}

Lung-protective mechanical ventilation strategies aim to reduce the incidence of ventilator-induced lung injury. These strategies typically center on delivering relatively low tidal volumes $\left(\mathrm{V}_{\mathrm{T}}\right)$ of $5-8 \mathrm{~mL} / \mathrm{kg}$ of predicted body weight $(\mathrm{PBW})$ and restricting plateau pressure $\left(\mathrm{P}_{\text {plat }}\right)$ to $30 \mathrm{~cm} \mathrm{H}_{2} \mathrm{O}^{1-4}$ In an influential analysis of data from ran-

\footnotetext{
Dr Baldomero is affiliated with the Department of Medicine, Pulmonary Section, Minneapolis VA Health Care System, Minneapolis, Minnesota. Drs Baldomero and Marini are affiliated with the Department of Medicine, Division of Pulmonary, Allergy, Critical Care, and Sleep Medicine, University of Minnesota, Minneapolis, Minnesota. Drs Skarda and Marini are affiliated with the Department of Medicine, Regions Hospital, St Paul, Minnesota. Dr Skarda is affiliated with the Department of Medicine, University of Minnesota, Minneapolis, Minnesota.
}

The authors disclose a relationship with HealthPartners Research Foundation domized trials of subjects with ARDS, Amato and colleagues reported that driving pressure $(\Delta \mathrm{P})$, the difference between $\mathrm{P}_{\text {plat }}$ and end-expiratory airway pressures assessed under passive conditions, was strongly linked to mortality risk. $^{5}$ The implicit inference of this association is that $\Delta \mathrm{P}$ could play a key causal role in ventilator-induced lung injury. Prompted by these persuasive data, recent literature suggests that optimization of $\Delta \mathrm{P}$ would be a Supplementary material related to this paper is available at http://
www.rcjournal.com.

Correspondence: Arianne K Baldomero MD, 1 Veterans Drive (Pulmonary 111-N), Minneapolis, MN 55417. E-mail: baldo004@umn.edu.

DOI: $10.4187 /$ respcare.06599 
better variable to target for lung protection at the bedside than those in prior use $\left(\mathrm{V}_{\mathrm{T}}\right.$ and $\left.\mathrm{P}_{\text {plat }}\right)$. Although a

See the Related Editorial on Page 1017

$\Delta \mathrm{P}$ of approximately $15 \mathrm{~cm} \mathrm{H}_{2} \mathrm{O}$ has been commonly interpreted as the upper limit of safe $\Delta \mathrm{P}$ for ARDS, the safety threshold is likely to vary among patients, and no specific numerical value has been prospectively tested for predictive accuracy.

Such questions need to be addressed for diverse patient populations. Failure to adhere to lung-protective ventilation strategies may lead to the development of ARDS $^{6}$ as well as encourage adverse postoperative outcomes in patients without overt lung disease. ${ }^{7,8}$ Comprehensive surveys have reported that accepted standards for lung-protective practices in mechanical ventilation are not followed consistently. ${ }^{9-11}$

$\Delta \mathrm{P}$, which is the difference between end-inspiratory plateau and PEEP, is numerically equivalent to $\mathrm{V}_{\mathrm{T}}$ divided by the respiratory system compliance $\left(\mathrm{C}_{\mathrm{RS}}\right)$, a parameter usually determined primarily by the number of functional alveoli. Therefore, it can reasonably be argued that $\Delta \mathrm{P}$ correlates better with functional ("baby") lung size than does $\mathrm{V}_{\mathrm{T}}$ referenced to PBW. Because $\Delta \mathrm{P}$ may be influenced not only by lung conditions but also by chest wall compliance, its absolute value may reflect body habitus, alterations in position, and muscular tone as well as tidal lung excursions and stretching forces imposed upon the alveoli.

Although $\Delta \mathrm{P}$ is theoretically appealing as a convenient guide for targeting safe ventilation, we currently do not know its usual range in patients receiving putatively safe $\mathrm{V}_{\mathrm{T}}$ and $\mathrm{P}_{\text {plat }}$, its variability in the same patient over time, or whether patients are currently being ventilated above or below proposed thresholds of safety for $\Delta \mathrm{P}$. Therefore, we sought to document over time the $\Delta \mathrm{P}$ ranges observed in current practice among mechanically ventilated subjects receiving routine care for diverse acute conditions in a community hospital environment.

\section{Methods}

\section{Study Design and Population}

In this retrospective, observational study, we reviewed the electronic medical records of 125 subjects who were mechanically ventilated for at least $24 \mathrm{~h}$ in the Medical and Surgical Intensive Care Units at Regions Hospital (St. Paul, MN) over a 12-month period spanning August 2013 to August 2014. The study was approved by the HealthPartners Institutional Review Board, which oversees research conducted at this site.

\section{QUICK LOOK}

\section{Current knowledge}

Driving pressure $(\Delta \mathrm{P})$, the difference between plateau pressure $\left(\mathrm{P}_{\text {plat }}\right)$ and end-expiratory airway pressure, has been reported to be strongly linked to mortality risk. Although its causative role has not yet been confirmed, a $\Delta \mathrm{P}$ of approximately $15 \mathrm{~cm} \mathrm{H}_{2} \mathrm{O}$ has been suggested as the upper limit of safe $\Delta \mathrm{P}$ for ARDS.

\section{What this paper contributes to our knowledge}

In a university-affiliated and house staff-aided institution with respiratory care protocols based on lung protective guidelines for $\left(\mathrm{V}_{\mathrm{T}}\right)$ and $\mathrm{P}_{\text {plat }}$, our data illustrate the mean amplitude and wide range of $\Delta \mathrm{P}$ among hospitalized subjects with diverse acute conditions. Targeting $\left(\mathrm{V}_{\mathrm{T}}\right)$ and $\mathrm{P}_{\text {plat }}$ alone may not align with current thinking regarding limitation of dynamic strain and injurious forces driving inflation. The suggested safety threshold for $\Delta \mathrm{P}$ is often violated by a strategy that focuses on only tidal volume and $\mathrm{P}_{\text {plat. }}$ Vigilance is especially important in the initial stages of mechanical ventilator support, and attention should be paid to triggering efforts when interpreting and comparing numerical values for $\Delta \mathrm{P}$.

\section{Data Collection}

Data collection included age, gender, race, weight, height, body mass index, mode of mechanical ventilation, set breathing frequency, set $\mathrm{V}_{\mathrm{T}}$, set PEEP, set $\mathrm{F}_{\mathrm{IO}_{2}}$, total breathing frequency, static $\mathrm{C}_{\mathrm{RS}}, \mathrm{P}_{\text {plat }}$, auto-PEEP, peak inspiratory pressures, exhaled minute ventilation, diagnosis for hospitalization, indication for initiation of mechanical ventilation, duration of mechanical ventilation, and medications used for sedation.

Our electronic medical record system (Epic, Madison WI) retains only caregiver-validated data. Therefore, all stored mechanical ventilator data had been collected, validated, and entered into the electronic medical record by trained respiratory therapists during routine care. At the time of data collection, the mechanical ventilator used was the Puritan Benett 840 Ventilator. Routine mechanical ventilator checks and measurements were performed every $4 \mathrm{~h}$, according to hospital protocol (see the supplementary materials at http://www.rcjournal.com). The recorded single-point measurements of parameters for mechanical ventilation (ie, set and observed breathing frequencies, PEEP, $\mathrm{F}_{\mathrm{IO}_{2}}$, static $\mathrm{C}_{\mathrm{RS}}, \mathrm{P}_{\text {plat }}$, auto-PEEP, peak inspiratory pressures, and exhaled minute ventilation) were extracted from the electronic medical record for each subject approximately every $8 \mathrm{~h}$ for a total of 3 assessment time points 
over the $24 \mathrm{~h}$ immediately following intubation. $\Delta \mathrm{P}$ values were calculated as $\Delta \mathrm{P}=\left(\mathrm{P}_{\text {plat }}-\mathrm{PEEP}_{\text {total }}\right)$, while $\mathrm{C}_{\mathrm{RS}}$ values were calculated as $\mathrm{C}_{\mathrm{RS}}=\mathrm{V}_{\mathrm{T}} /\left(\mathrm{P}_{\text {plat }}-\mathrm{PEEP}_{\text {total }}\right)$. All subjects were positioned with the head of the bed elevated to at least $30^{\circ}$. The algorithm of these ventilators for determining and displaying $\mathrm{P}_{\text {plat }}$ requires the absence of overt effort or instability during end-inspiratory circuit occlusion, but it does not assure entirely passive inflation (see the supplementary materials at http://www.rcjournal.com). To determine whether the subject was likely to be triggering the ventilator at the validated time point, the set breathing frequency was subtracted from the subject's observed breathing frequency. The subject was designated as triggering the ventilator (at least intermittently) if the difference between the between the subject's measured breathing frequency and set rate exceeded zero.

\section{Statistical Analysis}

Descriptive statistics were used to evaluate the demographic characteristics of the participants. The mean and standard deviation were used to summarize continuous measures, and the number and frequency were used to summarize categorical variables. Analysis of variance testing for repeated measures was used to compare the differences in mechanical ventilator parameters at 3 time points. In addition, adjustment for multiple comparisons by the Tukey test was used for pairwise comparisons at each time point. A 2-tailed, 2-sample $t$ test was used to evaluate the differences in mean $\Delta \mathrm{P}$ between passive versus active breaths and differences of data for female versus male subjects at each time point. Linear regression analysis was used to evaluate whether sex is associated with the variability in $\Delta \mathrm{P}$, adjusting for body mass index (continuous variable) and presence of chest wall restriction. Statistical significance was assigned to $P \leq .05$.

\section{Results}

The baseline characteristics of the subjects are presented in Table 1 . There was a statistically significant reduction of mean $\Delta \mathrm{P}$ from Time 1 versus Time $2(P<.001)$ and from Time 1 versus Time $3(P<.001)$, but no significant difference between Time 2 and Time $3(P=.16)$ (Figure 1). The proportions of all subjects exceeding $\Delta \mathrm{P}$ of $15.0 \mathrm{~cm} \mathrm{H}_{2} \mathrm{O}$ were $60 \%, 38 \%$, and $47 \%$ at Time 1 , Time 2 , and Time 3 , respectively. At Time 1, which was closest to initiation of mechanical ventilation, the group mean $\Delta \mathrm{P}$ was $16.1 \mathrm{~cm} \mathrm{H}_{2} \mathrm{O}$ (range 7.0-31.0 $\mathrm{cm} \mathrm{H}_{2} \mathrm{O}$ ). At Time 2, which was approximately $8 \mathrm{~h}$ after initiation of mechanical ventilation, the mean $\Delta \mathrm{P}$ decreased to $14.5 \mathrm{~cm} \mathrm{H}_{2} \mathrm{O}$ (range $7.0-35.0 \mathrm{~cm} \mathrm{H}_{2} \mathrm{O}$ ). At Time 3, which was approximately $16 \mathrm{~h}$ after initiation of mechanical ventilation, the mean $\Delta \mathrm{P}$ was $14.8 \mathrm{~cm} \mathrm{H}_{2} \mathrm{O}$ (range 8.0-32.0 $\mathrm{cm} \mathrm{H}_{2} \mathrm{O}$ ) (Table 2). The distribution of $\Delta \mathrm{P}$ among
Table 1. Baseline Characteristics

\begin{tabular}{|c|c|}
\hline \multicolumn{2}{|l|}{ Characteristics } \\
\hline Age, y & $61.8(15.5)$ \\
\hline Women & $65(52 \%)$ \\
\hline Black & $16(12.8 \%)$ \\
\hline White, non-Hispanic & $96(76.8 \%)$ \\
\hline White, Hispanic & $2(1.6 \%)$ \\
\hline Asian & $7(5.6 \%)$ \\
\hline Body mass index, $\mathrm{kg} / \mathrm{m}^{2}$ & $31.2(10.6)$ \\
\hline Height, cm & $166.9(10.9)$ \\
\hline Weight, kg & $86.6(29.3)$ \\
\hline \multicolumn{2}{|l|}{ Cardiac diseases at baseline } \\
\hline Coronary artery disease & $26(20.8 \%)$ \\
\hline Congestive heart failure & $26(20.8 \%)$ \\
\hline Atrial fibrillation & $20(16.0 \%)$ \\
\hline Valvular disease & $9(7.2 \%)$ \\
\hline \multicolumn{2}{|l|}{ Pulmonary diseases at baseline } \\
\hline COPD & $25(20.0 \%)$ \\
\hline OSA & $16(12.8 \%)$ \\
\hline Pulmonary hypertension & $5(4.0 \%)$ \\
\hline Asthma & $7(5.6 \%)$ \\
\hline Pulmonary embolism & $5(4.0 \%)$ \\
\hline Neuromuscular disease & $11(8.8 \%)$ \\
\hline \multicolumn{2}{|l|}{ Indication for mechanical ventilation } \\
\hline Altered mentation & $23(18.4 \%)$ \\
\hline Pneumonia & $21(16.8 \%)$ \\
\hline Sepsis & $19(15.2 \%)$ \\
\hline Cardiac arrest & $17(13.6 \%)$ \\
\hline Procedure/postoperative & $12(9.6 \%)$ \\
\hline ARDS & $9(7.2 \%)$ \\
\hline Acute pulmonary edema & $5(4.0 \%)$ \\
\hline Acute COPD/asthma exacerbation & $5(4.0 \%)$ \\
\hline Chronic respiratory failure & $3(2.4 \%)$ \\
\hline \multicolumn{2}{|l|}{ Respiratory and hemodynamic parameters } \\
\hline Assist-control mode, volume-control & $103(82.4 \%)$ \\
\hline Duration of mechanical ventilation, $\mathrm{d}$ & $5.9(11.2)$ \\
\hline Flow, L/min & $58.9(7.0)$ \\
\hline Set frequency, breaths/min & $15.2(4.0)$ \\
\hline $\mathrm{V}_{\mathrm{T}}, \mathrm{mL}$ & $514.0(81.5)$ \\
\hline $\mathrm{V}_{\mathrm{T}} / \mathrm{PBW}, \mathrm{mL} / \mathrm{kg}$ & $8.1(1.4)$ \\
\hline PEEP, $\mathrm{cm} \mathrm{H}_{2} \mathrm{O}$ & $6.3(2.2)$ \\
\hline $\mathrm{F}_{\mathrm{IO}_{2}}, \%$ & $54.0(22.2)$ \\
\hline $\mathrm{C}_{\mathrm{RS}}, \mathrm{mL} / \mathrm{cm} \mathrm{H} \mathrm{H}_{2} \mathrm{O}$ & $41.3(16.8)$ \\
\hline Minute ventilation, $\mathrm{L}$ & $9.3(3.0)$ \\
\hline Plateau pressure, $\mathrm{cm} \mathrm{H}_{2} \mathrm{O}$ & $21.5(5.2)$ \\
\hline Peak inspiratory pressure, $\mathrm{cm} \mathrm{H}_{2} \mathrm{O}$ & $27.1(5.2)$ \\
\hline Mean airway pressure, $\mathrm{cm} \mathrm{H}_{2} \mathrm{O}$ & $12.4(3.1)$ \\
\hline $\begin{array}{l}N=125 \text { subjects. Data are presented as mean }(\mathrm{SD}) \text { or } \\
\mathrm{V}_{\mathrm{T}}=\text { tidal volume } \\
\text { OSA }=\text { obstructive sleep apnea } \\
\mathrm{PBW}=\text { predicted body weight } \\
\mathrm{C}_{\mathrm{RS}}=\text { respiratory system compliance }\end{array}$ & \\
\hline
\end{tabular}

mechanically ventilated subjects at Time 1 , Time 2 , and Time 3 are shown in Figure 1.

At all time points, the median $\Delta \mathrm{P}$ was higher for passive breaths compared to breaths delivered to subjects who 


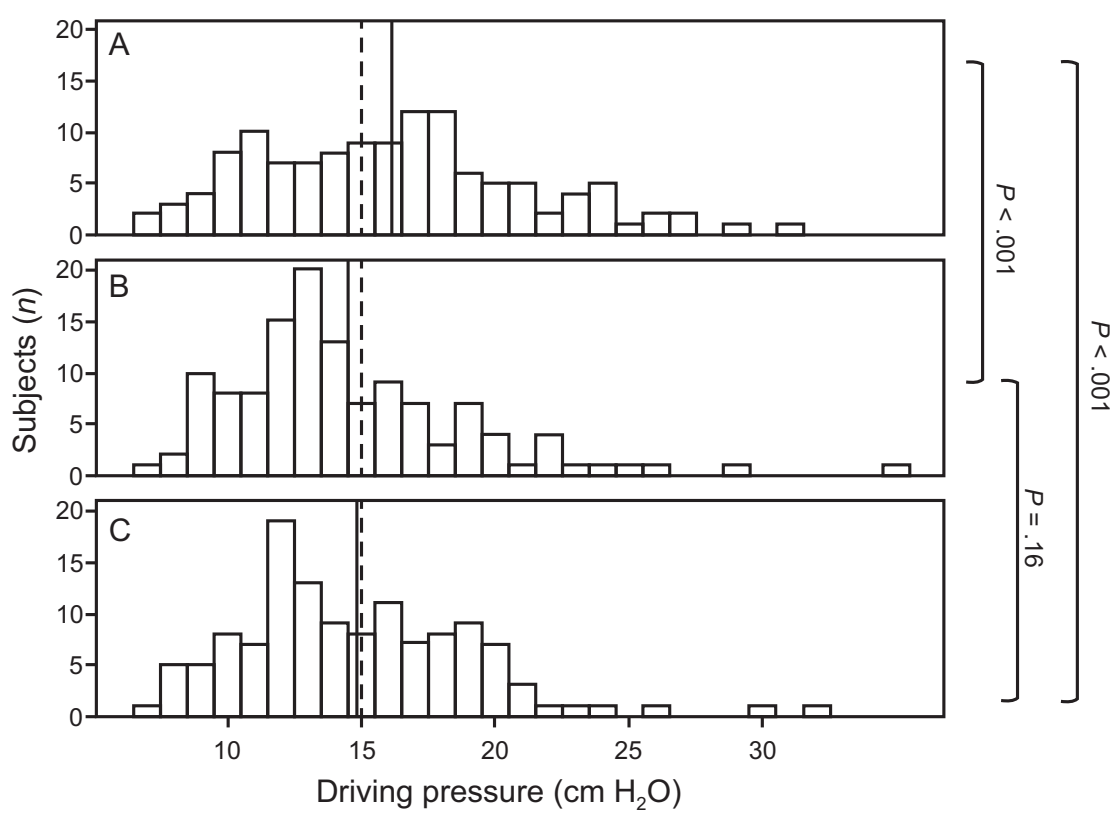

Fig. 1. Distribution of driving pressure among mechanically ventilated subjects at 3 different time points (A: Time 1, B: Time 2, and C: Time 3). The dashed line marks $\Delta \mathrm{P}$ of $15.0 \mathrm{~cm} \mathrm{H}_{2} \mathrm{O}$, and the solid black line marks the mean driving pressure at each time point.

Table 2. $\Delta \mathrm{P}$ and $\mathrm{C}_{\mathrm{RS}}$ at Time 1 , Time 2, and Time 3

\begin{tabular}{|c|c|c|c|}
\hline & \multicolumn{2}{|c|}{$\Delta \mathrm{P}$} & \multirow{2}{*}{$\begin{array}{c}\mathrm{C}_{\mathrm{RS}} \\
\text { Mean (SD), } \\
\text { mL/cm H } \mathrm{H}_{2} \mathrm{O}\end{array}$} \\
\hline & $\begin{array}{l}\text { Mean (SD), } \\
\mathrm{cm} \mathrm{H}_{2} \mathrm{O}\end{array}$ & $\begin{array}{l}\text { Range, } \\
\mathrm{cm} \mathrm{H}_{2} \mathrm{O}\end{array}$ & \\
\hline Time 1 & $16.1(5.0)$ & $7.0-31.0$ & $33.4(16.4)$ \\
\hline Time 2 & $14.5(4.5)^{*}$ & $7.0-35.0$ & $39.7(16.0) \ddagger \|$ \\
\hline Time 3 & $14.8(4.3)^{* \dagger}$ & $8.0-32.0$ & $40.1(16.3) \S$ \\
\hline \multicolumn{4}{|c|}{$\begin{array}{l}* P<.001 \text { compared to Time } 1 . \\
\dagger P=.16 \text { compared to Time } 3 . \\
¥ P=.004 \text { compared to Time } 1 . \\
\S P=.002 \text { compared to Time } 1 . \\
\| P=.86 \text { compared to Time } 3 . \\
\Delta \mathrm{P}=\text { driving pressure } \\
\mathrm{C}_{\mathrm{RS}}=\text { respiratory system compliance }\end{array}$} \\
\hline
\end{tabular}

were likely to be triggering (at least intermittently) at the time of data entry while mechanically ventilated in the volume assist-control mode (Fig. 2). The mean (SD) $\Delta \mathrm{P}$ values at Time 1 were 17.2 (4.0) versus $14.9(4.1) \mathrm{cm} \mathrm{H}_{2} \mathrm{O}$ $(P=.01)$ for passive versus triggered breathing, respectively. The mean $\Delta \mathrm{P}$ values were 15.2 (4.1) versus $13.7(4.1) \mathrm{cm} \mathrm{H}_{2} \mathrm{O}(P=.060)$ at Time 2 and $15.5(4.1)$ versus $14.2(4.0) \mathrm{cm} \mathrm{H}_{2} \mathrm{O}(P=.07)$ at Time 3 for passive versus triggered breathing, respectively.

At all time points, the mean $\Delta \mathrm{P}$ values of females were higher than those of males (Fig. 3). The mean $\Delta \mathrm{P}$ of females were 17.1, 15.4, and $15.8 \mathrm{~cm} \mathrm{H}_{2} \mathrm{O}$, while the mean $\Delta \mathrm{P}$ of males were $15.1,13.5$, and $13.9 \mathrm{~cm} \mathrm{H}_{2} \mathrm{O}$ at Time 1 , Time 2, and Time 3, respectively (Table 3).

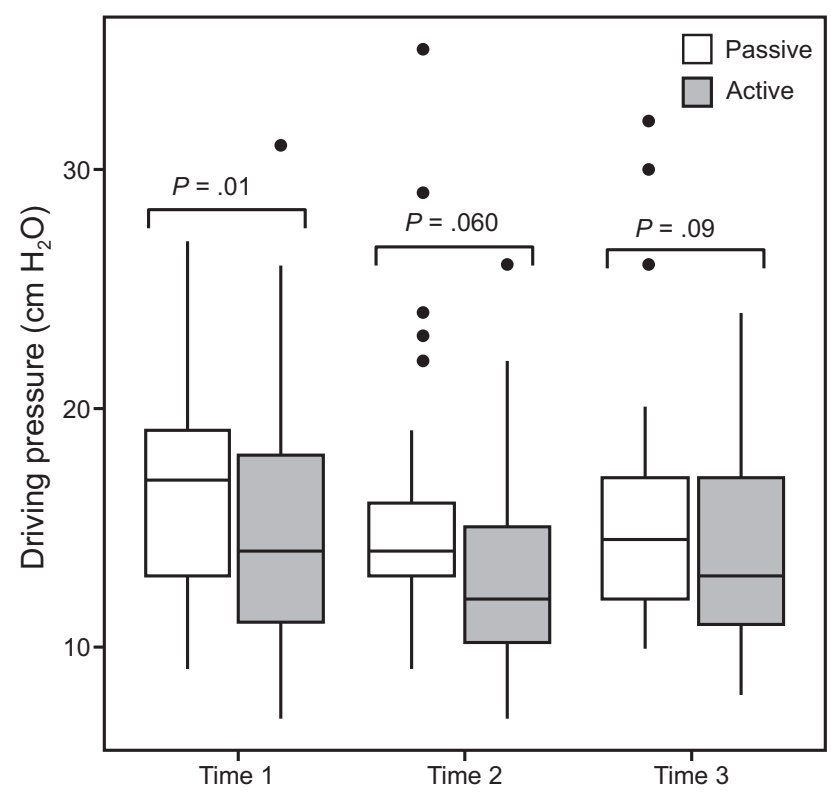

Fig. 2. Driving pressure at 3 time points comparing mechanically ventilated subjects on volume assist-control mode during passive versus active breathing. Horizontal lines represent the median driving pressure.

The values for set PEEP and $\mathrm{P}_{\text {plat }}$ (Time 2 and Time 3) were similar for female and male subjects (Table 3 ). However, males had higher minute ventilation and compliance values compared to females. The $\Delta \mathrm{P}$ and the $\mathrm{V}_{\mathrm{T}} / \mathrm{PBW}$ of males compared to females were also lower.

After controlling for body mass index, possible associated chest wall restriction, and $\mathrm{V}_{\mathrm{T}} / \mathrm{PBW}$, the adjusted odds 


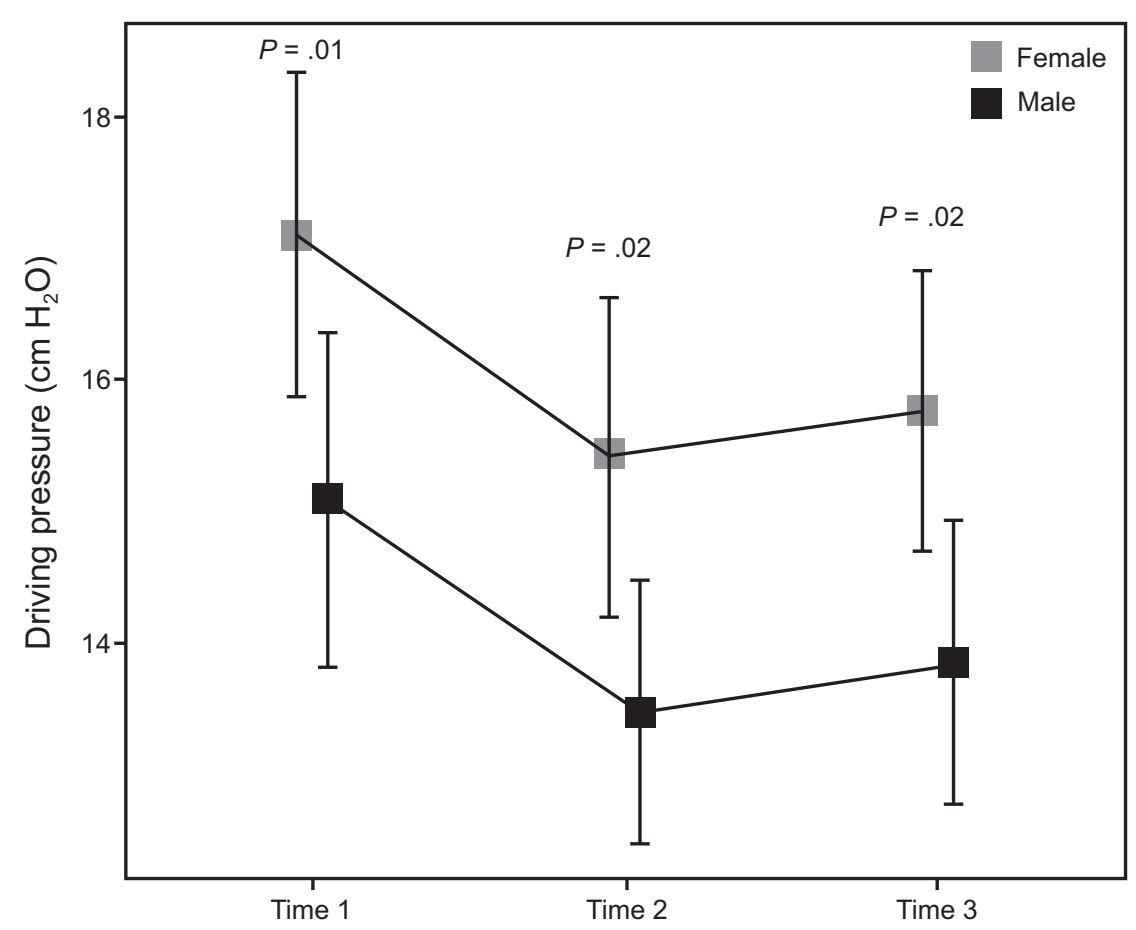

Fig. 3. Mean driving pressure for females versus males at Time 1, Time 2, and Time 3. Vertical lines show confidence intervals.

ratio (adjusted OR) for every $1-\mathrm{cm}_{2} \mathrm{O}$ increase in $\Delta \mathrm{P}$ is higher for females compared to males (adjusted OR 1.97, 95\% CI 1.05 to $3.73, P=.036$ ) (Table 4).

The mean $\mathrm{C}_{\mathrm{RS}}$ was lowest at Time 1 (Table 2). The mean (SD) $\mathrm{C}_{\mathrm{RS}}$ values were 33.4 (16.4), 39.7 (16.0), and 40.1 (16.3) $\mathrm{mL} / \mathrm{cm} \mathrm{H}_{2} \mathrm{O}$ at Time 1 , Time 2 , and Time 3 , respectively.

Although there appears to be an increasing trend in $\Delta \mathrm{P}$ with increasing body mass index, as illustrated in the scatter plots of $\Delta \mathrm{P}$ versus body mass index, there was a very limited number of subjects with body mass index $>40 \mathrm{~kg} / \mathrm{m}^{2}$ in our subject sample, which precludes this determination (Fig. 4).

\section{Discussion}

In a university-affiliated and house staff-aided institution using respiratory care protocols based on lungprotective guidelines for $\mathrm{V}_{\mathrm{T}}$ and $\mathrm{P}_{\text {plat }}$ (see the supplementary materials at http://www.rcjournal.com), our data illustrate the mean amplitude and wide range of $\Delta \mathrm{P}$ among hospitalized, ventilated subjects with diverse acute conditions. These data emphasize that targeting $\mathrm{V}_{\mathrm{T}}$ and $\mathrm{P}_{\text {plat }}$ alone may not align with current thinking regarding dynamic strain and injurious driving forces. ${ }^{12}$

A safe value for $\Delta \mathrm{P}$ is currently undefined and will vary across patients according to variables such as chest wall characteristics and position. Although this has yet to be determined prospectively, the suggested safe upper threshold value for $\Delta \mathrm{P}$ (ie, $<15.0 \mathrm{~cm} \mathrm{H}_{2} \mathrm{O}$ ) has already been incorporated into many care protocols worldwide. This was not, however, implemented at our own institution at the time of data collection. Our data, which preceded the publication of reports urging closer attention to $\Delta \mathrm{P},{ }^{5}$ suggest that while safe $\mathrm{V}_{\mathrm{T}}$ and $\mathrm{P}_{\text {plat }}$ were recognized and well-respected goals of our ventilator management, $\Delta \mathrm{P}$ often exceeded the currently suggested $<15 \mathrm{~cm} \mathrm{H}_{2} \mathrm{O}$ guideline. We found that the recorded $\Delta \mathrm{P}$ among these subjects ranged from 7.0 to $35.0 \mathrm{~cm} \mathrm{H}_{2} \mathrm{O}$, with up to $60 \%$ ventilated with $\Delta P \geq 15.0 \mathrm{~cm} \mathrm{H}_{2} \mathrm{O}$ at the time of initiating mechanical ventilator support (Time 1). With $\mathrm{V}_{\mathrm{T}}$ unvarying, $\Delta \mathrm{P}$ changed during the first $24 \mathrm{~h}$, with the mean $\Delta \mathrm{P}$ statistically highest within the first $8 \mathrm{~h}$ of initiating mechanical ventilation. Improved $C_{\mathrm{RS}}$, likely relating to gradual lung recruitment, treatment of the underlying acute illnesses, and adjustment in level of sedation, may account for the reduction in $\Delta \mathrm{P}$ in later time periods. Our sample included too few subjects with body mass index $>40 \mathrm{~kg} / \mathrm{m}^{2}$ to attempt a valid correlation of $\Delta \mathrm{P}$ to massive obesity. In addition, morbid obesity and other conditions that alter chest wall compliance can contribute to pleural pressure, and can therefore cause "elevated" $P_{\text {plat }}$ measurements. Thus, careful interpretation of these measurements is warranted.

Although valid $\Delta \mathrm{P}$ measurements can only be obtained when the subject achieves a stable end-inspiratory plateau and does not breathe actively during circuit closure (the machine algorithm precludes the latter), we noted that some subjects triggered the ventilator around the approximate times when the $\Delta \mathrm{P}$ measurements were recorded. Subjects on volume-control mode who were presumed to be at least intermittently triggering assisted breaths had somewhat lower 
Table 3. Mechanical Ventilator Parameters Comparing Females vs Males

\begin{tabular}{|c|c|c|c|}
\hline & Time 1 & Time 2 & Time 3 \\
\hline \multicolumn{4}{|c|}{$\Delta \mathrm{P}, \mathrm{cm} \mathrm{H}_{2} \mathrm{O}$} \\
\hline Female & $17.1(5.0)$ & $15.4(4.9)$ & $15.8(4.3)$ \\
\hline Male & $15.1(4.9)$ & $13.5(3.9)$ & $13.9(4.2)$ \\
\hline$P$ & .01 & .02 & .02 \\
\hline \multicolumn{4}{|l|}{$\mathrm{V}_{\mathrm{T}}, \mathrm{mL}$} \\
\hline Female & $483.5(74.2)$ & $474.4(67.0)$ & $472.1(63.4)$ \\
\hline Male & $566.7(66.9)$ & $548.9(76.8)$ & $554.8(79.7)$ \\
\hline$P$ & $<.001$ & $<.001$ & $<.001$ \\
\hline \multicolumn{4}{|c|}{$\mathrm{V}_{\mathrm{T}} / \mathrm{PBW}, \mathrm{mL} / \mathrm{kg}$} \\
\hline Female & $9.3(1.6)$ & $9.0(1.5)$ & $8.9(1.4)$ \\
\hline Male & $8.1(1.0)$ & $7.8(1.1)$ & $7.9(1.1)$ \\
\hline$P$ & $<.001$ & $<.001$ & .001 \\
\hline \multicolumn{4}{|c|}{ Minute ventilation, $\mathrm{L}$} \\
\hline Female & $8.2(2.06)$ & $8.2(2.3)$ & $8.6(2.1)$ \\
\hline Male & $10.3(3.0)$ & $10.3(3.6)$ & $10.5(3.3)$ \\
\hline$P$ & $<.001$ & $<.001$ & $<.001$ \\
\hline \multicolumn{4}{|c|}{ Set PEEP, $\mathrm{cm} \mathrm{H}_{2} \mathrm{O}$} \\
\hline Female & $6.1(2.0)$ & $6.3(2.2)$ & $6.2(2.0)$ \\
\hline Male & $6.2(2.0)$ & $6.6(2.3)$ & $6.6(2.5)$ \\
\hline$P$ & .83 & .57 & .22 \\
\hline \multicolumn{4}{|c|}{ Plateau pressure, $\mathrm{cm} \mathrm{H}_{2} \mathrm{O}$} \\
\hline Female & $23.2(5.3)$ & $21.8(5.4)$ & $21.9(4.5)$ \\
\hline Male & $21.2(5.6)$ & $21.0(4.9)$ & $20.5(5.1)$ \\
\hline$P$ & .03 & .06 & .12 \\
\hline \multicolumn{4}{|c|}{$\mathrm{C}_{\mathrm{RS}}, \mathrm{mL} / \mathrm{cm} \mathrm{H} \mathrm{H}_{2} \mathrm{O}$} \\
\hline Female & $33.0(13.0)$ & $37.5(14.6)$ & $34.6(11.9)$ \\
\hline Male & $45.8(18.2)$ & $48.7(14.8)$ & 48.7 (20.6) \\
\hline$P$ & $<.001$ & $<.001$ & $<.001$ \\
\hline \multicolumn{4}{|l|}{$\mathrm{F}_{\mathrm{IO}_{2}}, \%$} \\
\hline Female & $69.9(24.8)$ & $45.3(12.6)$ & 41.5 (11.4) \\
\hline Male & $73.2(24.9)$ & $48.9(17.1)$ & $45.4(15.2)$ \\
\hline$P$ & .32 & .27 & .25 \\
\hline $\begin{array}{l}\text { Data are pres } \\
\Delta \mathrm{P}=\text { driving } \\
\mathrm{V}_{\mathrm{T}}=\text { tidal vo } \\
\mathrm{PBW}=\text { predi } \\
\mathrm{C}_{\mathrm{RS}}=\text { respira }\end{array}$ & & & \\
\hline
\end{tabular}

Table 4. Odds Ratios Comparing Females vs Males

\begin{tabular}{lcccl}
\hline \hline & Unadjusted & $P$ & Adjusted & \multirow{2}{*}{ OR $(95 \% \mathrm{CI})$} \\
& OR (95\% CI) & $P$ & $P$ \\
\hline Female vs Male & $2.04(1.10,3.82)$ & .02 & $1.86(0.99,3.52) *$ & .054 \\
& & & $2.17(1.17,4.07) \dagger$ & .02 \\
& & & $1.97(1.05,3.73) \dagger$ & .036
\end{tabular}

Odds ratios for every $1-\mathrm{cm} \mathrm{H}_{2} \mathrm{O}$ increase in $\Delta \mathrm{P}$ at Time 1

* Adjusted model includes body mass index and presence of chest wall restriction as covariates.

$\dagger$ Adjusted model includes tidal volume/predicted body weight as a covariate.

$\ddagger$ Adjusted model includes body mass index, presence of chest wall restriction, and tidal volume/predicted body weight as covariates.

$\mathrm{OR}=$ odds ratio
$\Delta \mathrm{P}$ values compared to subjects who were not making respiratory efforts. Current generation ventilators will display a $\mathrm{P}_{\text {plat }}$ if the subject is gently triggering the assisted breath. Perhaps it is worth noting that virtually none of the randomized clinical trials in the literature addressing ventilator settings, including the most influential in current practice, rigidly assured passive breathing before data recording.

In our study, females had higher $\Delta \mathrm{P}$ than males with similar set values for PEEP, but the $\Delta \mathrm{P}$ was not statistically different (adjusted odds ratio 1.86, 95\% CI .99 to $3.52, P=.054$ ) between females and males after adjusting for body mass index and presence of chest wall restriction (Table 4). Although the observed compliance values of female subjects were $>10 \mathrm{~mL} / \mathrm{cm} \mathrm{H}_{2} \mathrm{O}$ lower than those of male subjects, there is little reason to believe that specific compliance of the lung and principles of $\Delta \mathrm{P}$ containment and ventilator-induced lung injury avoidance are genderspecific. Females are known to have smaller lung volumes by $10-12 \%$ compared to males, and therefore lower chest compliance, based on previously published work. ${ }^{13}$

Our population sample included only small numbers of subjects with ARDS. Force amplifiers place the lung tissues of such patients at increased injury risk and might lower the real threshold for safe $\Delta \mathrm{P}$. On the other hand, it appears from available evidence that subjects without ARDS also may be harmed by $\Delta \mathrm{P}$ values that are not closely regulated to be lung-protective. ${ }^{14}$

Our study has a number of noteworthy limitations. First, this is a retrospective survey with a relatively small sample size. Second, the $\Delta \mathrm{P}$ values are based on airway rather than transpulmonary pressure measurements, which conceptually are more precisely relevant to lung protection. Third, our data set was limited to the first $24 \mathrm{~h}$ after initiating mechanical ventilator support. Fourth, on average, our subjects were ventilated with $\mathrm{V}_{\mathrm{T}}$ approaching the upper boundary of lung-safe $\mathrm{V}_{\mathrm{T}}$. Fifth, although we collected data on sedation, the specific data on medication dosing, strategies (bolus vs continuous infusion), and timing of sedation administration were not recorded. Sixth, clinically relevant outcomes such as ventilator-free days, ICU and hospital lengths of stay, and mortality are not presented in this study. Finally, as a relatively minor concern, the range of set PEEP values was relatively narrow.

Despite these limitations, this analysis does allow conclusions to be drawn with potentially important implications. The currently suggested safety threshold for $\Delta \mathrm{P}$ is often violated by a strategy that focuses only on boundaries for $\mathrm{V}_{\mathrm{T}}$ or $\mathrm{P}_{\text {plat }}$. Our findings, obtained in a diverse population of intubated subjects, extend observations and concerns for patients with ARDS. ${ }^{5}$ Should numerical values for $\Delta \mathrm{P}$ based on airway pressure alone prove in prospective trials to be the key variable to constrain, vigilance would appear to be especially important in the initial stages of mechanical ventilator sup- 

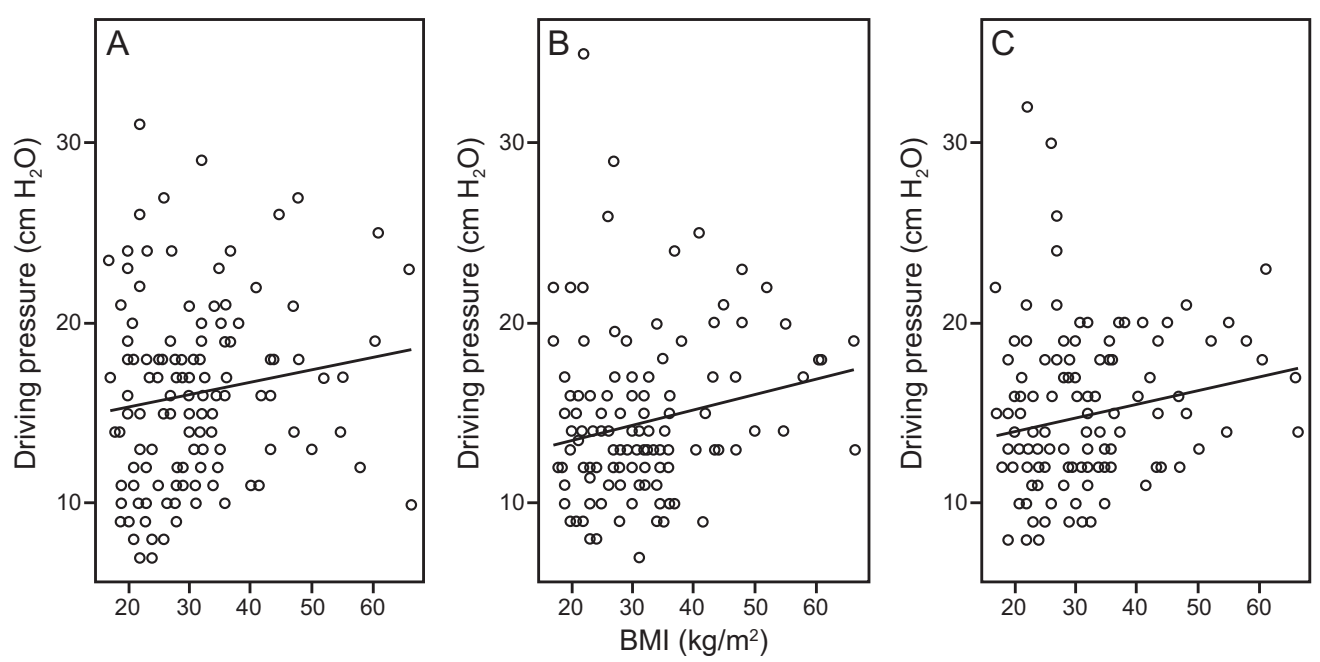

Fig. 4. Scatter plots of driving pressure versus body mass index at A: Time 1, B: Time 2, and C: Time 3. BMI = body mass index.

port. Finally, attention should be paid to triggering efforts when interpreting and comparing numerical values of $\Delta \mathrm{P}$.

\section{REFERENCES}

1. Brower RG, Matthay MA, Morris A, et al. Ventilation with lower tidal volumes as compared with traditional tidal volumes for acute lung injury and the acute respiratory distress syndrome. N Engl J Med 2000;342(18):1301-1308.

2. Brower RG, Lanken PN, MacIntyre N, Matthay MA, Morris A, Ancukiewicz M, et al. Higher versus lower positive end-expiratory pressures in patients with the acute respiratory distress syndrome. N Engl J Med 2004;351(4):327-336.

3. Meade MO, Cook DJ, Guyatt GH, Slutsky AS, Arabi YM, Cooper DJ, et al. Ventilation strategy using low tidal volumes, recruitment maneuvers, and high positive end-expiratory pressure for acute lung injury and acute respiratory distress syndrome: a randomized controlled trial. JAMA 2008;299(6):637-645.

4. Mercat A, Richard JC, Vielle B, Jaber S, Osman D, Diehl JL, et al. Positive end-expiratory pressure setting in adults with acute lung injury and acute respiratory distress syndrome: a randomized controlled trial. JAMA 2008;299(6):646-655.

5. Amato MB, Meade MO, Slutsky AS, Brochard L, Costa EL, Schoenfeld DA, et al. Driving pressure and survival in the acute respiratory distress syndrome. N Engl J Med 2015;372(8):747-755.

6. Gajic O, Frutos-Vivar F, Esteban A, Hubmayr RD, Anzueto A. Ventilator settings as a risk factor for acute respiratory distress syndrome in mechanically ventilated patients. Intensive Care Med 2005; 31(7):922-926.

7. PROVE Network Investigators for the Clinical Trial Network of the European Society of Anaesthesiology, Hemmes SN, Gama de Abreu
M, Pelosi P, Schultz MJ. High versus low positive end-expiratory pressure during general anaesthesia for open abdominal surgery (PROVHILO trial): a multicentre randomised controlled trial. Lancet. 2014;384(9942):495-503.

8. Park SH. Perioperative lung-protective ventilation strategy reduces postoperative pulmonary complications in patients undergoing thoracic and major abdominal surgery. Korean J Anesthesiol 2016;69(1):3-7.

9. Neto AS, Hemmes SN, Barbas CS, Beiderlinden M, FernandezBustamante A, Futier E, et al. Association between driving pressure and development of postoperative pulmonary complications in patients undergoing mechanical ventilation for general anaesthesia: a meta-analysis of individual patient data. Lancet Respir Med 2016;4(4):272-280.

10. Weinert CR, Gross CR, Marinelli WA. Impact of randomized trial results on acute lung injury ventilator therapy in teaching hospitals. Am J Respir Crit Care Med 2003;167(10):1304-1309.

11. Bellani G, Laffey JG, Pham T, Fan E, Brochard L, Esteban A, et al. Epidemiology, patterns of care, and mortality for patients with acute respiratory distress syndrome in intensive care units in 50 countries. JAMA 2016;315(8):788-800.

12. Marini JJ, Jaber S. Dynamic predictors of VILI risk: beyond the driving pressure. Intensive Care Med 2016;42(10):1597-1600.

13. Bellemare F, Jeanneret A, Couture J. Sex differences in thoracic dimensions and configuration. Am J Respir Crit Care Med 2003; 168(3):305-312.

14. Serpa Neto A, Hemmes SN, de Abreu MG, Pelosi P, Schultz MJ, PROVE Network Investigators. Protocol for a systematic review and individual patient data meta-analysis of benefit of so-called lungprotective ventilation settings in patients under general anesthesia for surgery. Syst Rev 2014;3:2.

This article is approved for Continuing Respiratory Care Education credit. For information and to obtain your CRCE

(free to AARC members) visit www.rcjournal.com

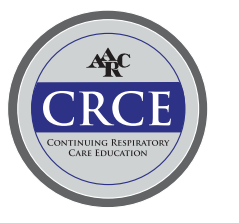

